The tap roots bore a less variable but denser population, mainly of sporing fungi, but of different quality from the fungi appearing on Warcup soil plates made with soil from pots in which the plants had grown. Fungi were often absent on growing apices; but as the roots aged the population of fungi appearing on plates increased in numbers and was dominated by sporing fungi.

In another experiment seedlings were grown in beechwood soil but in light intensities ranging from $25 \cdot 1$ to $3 \cdot 6$ per cent daylight. Shading not only resulted in a decrease in the dry weight, free sugar content and the extent of mycorrhizal infection of the seedlings but led also to profound changes in the nature of the surface populations of main and lateral roots. However, these effects cannot be attributed to light alone but to other factors also, such as humidity and temperature.

The numbers of Rhizoctonia spp. and Trichoderma viride were favoured by decreasing and increasing radiation respectively. Rhizoctonia, which is pathogenic to seedlings, was antagonized on the sampling plates by Trichoderma, and as the season advanced and mycorrhizas developed, the numbers of the antagonist increased, while those of the pathogen decreased. There was evidence, however, that Trichoderma did not entirely determine the numbers of Rhizoctonia on the roots. It was indicated that the condition of the host plant plays a major part in determining the nature of its surface flora and that the observations were limited by the fact that a cultural technique was employed which favoured Trichoderma.

J. K. BrinRley

J. S. WAID

J. M. WILSON

\section{FIELD BIOLOGY AT THE KING EDWARD VI GRAMMAR SCHOOL, CAMP HILL, BIRMINGHAM}

$\mathrm{K}^{\mathrm{i}}$

ING Edward VI Grammar School, Camp Hill, Birmingham, has recently published a full report by its Natural History Society of a comprehensive survey of a selected area named for convenience Brown's Coppice, the actual name of the principal woodland on the site ("Brown's Coppice: a Survey". Pp. 79. Obtainable from The Secretary, The Natural History Society, King Edward VI Grammar School for Boys, Camp Hill, Birmingham. 5s. including postage). The site is about 130 acres in extent, and comprises eight distinct habitats. Forty members of the Society took part in the survey. The studies were divided into nine sections-botany, zoology, ornithology, entomology, edaphic factor, cartography, specialized photography, geography and local history; and a member was appointed to supervise the work of each section. (Later a pond section, devoted to the study of a flooded bomb crater, was added.)

The report is divided into three parts. Part 1 (Physical Features) deals with geography-general and regional setting, relief, drainage and climate; and land utilization-local history and agriculture. This report is commendably thorough, the first chapter being accompanied by six maps and figures and the second by two maps.

Part 2 (Dependent Factors) reports ecological studies -index of habitats, edaphic factor, biotic factor (plant and animal). The habitats included woodland (40 acres), bog (20 acres), pasture (20 acres), hedgerows, standing water (1 acre) and waste land (about 4 acres). This is accompanied by ten maps, transects and quadrats.

Part 3 (Natural History) covers the main groups of the flora and fauna. Twelve pages are needed to list the plants identified, and these are accompanied by six plates. The various fungi, too, are listed. Some good work in bacteriology is also reported, and this is of particular interest since the subject usually receives such scant treatment in schools. Similar detailed treatment is afforded to the fauna, including invertebrates and mammals; separate chapters are devoted to insects and birds. Further plates illustrate a giant puffball, two birds, a photomicrograph of a blow-fly and one of Cyclops.

Three appendixes complete this report, which is the most comprehensive and thorough of its kind which we have seen produced by a school. King Edward VI Grammar School, Camp Hill, Birmingham, is to be congratulated on a very worthy effort.

\section{COMPARATIVE PERFORMANCE OF NICKEL AND POROUS ALUMINA SAMPLE HOLDERS FOR DIFFERENTIAL THERMAL ANALYSIS}

DURING a comparative evaluation of the performance, under identical conditions, of porous sintered alumina and nickel specimen holders for use in differential thermal analysis, it was observed that for certain reactions involving the evolution of a gas, such as the thermal decomposition of a calcium hydroxide $\left(\mathrm{Ca}(\mathrm{OH})_{2}\right)$ and calcium carbonate $\left(\mathrm{CaCO}_{3}\right)$ and mixtures of these two compounds, the significant linear portion of the downsweep of the peak occurred at appreciably higher temperatures when using a nickel block than when using an alumina block of identical dimensions. The cylindrical sample holders used were $41 \mathrm{~mm}$. high and $38 \mathrm{~mm}$. in diameter, with sample wells $13 \mathrm{~mm}$. wide and $19 \mathrm{~mm}$. deep. A linear heating rate of $15^{\circ} \mathrm{C}$. per min. was employed.

The curves obtained using the two types of sample holder are superimposed to facilitate interpretation (Fig. 1). The peak displacement observed is illustrated in curve 1 for a calcium hydroxide-calcium carbonate mixture, and in curve 2 for pure calcium carbonate.

This anomaly could not be accounted for by considerations of thermal conductivity or heat capacity, and it was also found that the peaks due to phasechanges such as the $\alpha-\beta$ quartz transformation ${ }^{1}$ and the rhombic-trigonal inversion in strontium carbonate ${ }^{2}$ showed no such displacement. This suggested that loss of gas in the decomposition of calcium hydroxide and carbonate might be responsible for the anomaly, in that the pores in the alumina sample holder permitted the escape of the gaseous decomposition products, lowering the concentration of the gas in the mass of sample, and so leading to the more rapid completion of the reaction. Following the reasoning that if the porous alumina block could be rendered impermeable to gas this effect would be eliminated, thin impervious linings of vitreous silica were fitted to the sample wells in the alumina block. In this modified block, the anomaly disappeared, as shown in curves 3 and 4, respectively, for calcium hydroxide and calcium carbonate. Bearing in mind 